\title{
SEMBLANZAS *
}

* Esta sección pretende mantener viva la memoria de algunos ilustres maestros del Derecho Político español y se inició con la publicación en el n. ${ }^{\circ} 18$ de la semblanza de Nicolás Pérez Serrano, y en el n. ${ }^{\circ} 23$ de Manuel García Pelayo. Bajo la coordinación del Catedrático de Derecho Constitucional de la Universidad de Oviedo y director del seminario de Historia Constitucional «Martínez Marina», Joaquín Varela Suanzes-Carpegna, a quien agradecemos muy sinceramente todo su esfuerzo y trabajo, se publicaron las de Adolfo Posada (n. ${ }^{\circ}$ 25), Ramón de Salas (n. ${ }^{\circ} 28$ ), Fernando de los Ríos (n. ${ }^{\circ} 30$ ) y Manuel Colmeiro (n. $\left.{ }^{\circ} 31\right)$. TRC continuará publicando estas semblanzas de antiguos profesores de nuestra asignatura y en el n. ${ }^{\circ} 36$ insertaremos la semblanza de Antonio Alcalá Galiano, de la pluma del Catedrático de Derecho Constitucional de la Universidad de Murcia, Ángel Garrorena Morales. 



\title{
UN INFLUYENTE MAESTRO DEL DERECHO POLÍTICO ESPAÑOL: VICENTE SANTAMARÍA DE PAREDES (1853-1924)
}

\author{
JOAQUÍN VARELA SUANZES-CARPEGNA \\ Catedrático de Derecho Constitucional \\ Universidad de Oviedo
}

SUMARIO

I. Un catedrático adscrito al «liberalismo armónico».

II. El Curso de Derecho Político y otros escritos jurídicos y sociológicos.

III. Parlamentario, ministro y preceptor regio.

\section{UN CATEDRÁTICO ADSCRITO AL «LIBERALISMO ARMÓNICO»}

Vicente Santamaría de Paredes nació en Madrid el 17 de mayo de 1853. Reinaba entonces Isabel II y presidía el Gobierno el General Lersundi, que en septiembre de ese mismo año se lo cedería a José Luis Sartorius, Conde de San Luis, quien lo retendría hasta julio de 1854 , cuando la «Vicalvarada» puso fin a la «Década Moderada» y dio comienzo el «Bienio Progresista».

Santamaría tenía casi la misma edad, año más, año menos, que Santiago Ramón y Cajal, Leopoldo Alas «Clarín», Emilia Pardo Bazán, José Canalejas y Marcelino Menéndez Pelayo, por citar tan sólo a algunos distinguidos coetáneos en el ámbito de la ciencia, de las letras y de la política españolas. Entre siete y diez años mayores que él eran, en cambio, Joaquín Costa y Benito Pérez Galdós, mientras que Adolfo Posada y Miguel de Unamuno nacerían entre siete y once años después.

Huérfano de padre y madre a los 10 años $^{1}$, «quedando en desamparo de bienes de fortuna» ${ }^{2}$, Santamaría hubo de dedicarse desde muy niño intensamente al estu-

1 Cfr. G. DÍAZ DÍAZ, Vicente Santamaría de Paredes, en «Hombres y documentos de la filosofía española», Centro Superior de Investigaciones Científicas, Instituto de Historia, Madrid, 2003, vol. 7. ${ }^{\text {p. }} 175$.

2 J. SÁNCHEZ DE TOCA, Discurso necrológico del Excmo. Sr. Don Vicente Santamaría de Paredes, Establecimiento tipográfico de Jaime Ratés, Madrid, 1924, p. 6. 
dio. Para ello contó con el apoyo y consejo de su tutor, Pablo Canales, su «segundo padre», como confesaría en la dedicatoria de su ensayo La Defensa del derecho de propiedad y sus relaciones con el trabajo, premiado en 1872 por la Real Academia de Ciencias Morales y Políticas, presidida a la sazón por Antonio de los Ríos Rosas, y publicado en Madrid dos años más tarde. En la portadilla de esta obra juvenil se recogía el dictum del economista Bastiat, que Santamaría haría suyo: «los intereses legítimos son armónicos» ${ }^{3}$.

Tras obtener el título de profesor mercantil en junio de 1868, el mismo año en que la «Gloriosa revolución» de septiembre llevaría al destierro a la Reina, comenzó los estudios de Derecho Civil y Canónico en la Universidad Central durante los densos años del «Sexenio Democrático». En septiembre de 1872 se licencia y en junio de 1873, pocos meses después de proclamarse la I República, obtuvo el título de doctor en Derecho Civil y Canónico con premio extraordinario, al que también aspiraba Joaquín Costa ${ }^{4}$.

La Facultad de Derecho de aquella Universidad contaba con algunos ilustres profesores, como Francisco Giner de los Ríos en Filosofía del Derecho, y Gumersindo de Azcárate en Legislación Comparada. Pese a que no dispongamos de unas memorias, ni siquiera de unos meros apuntes autobiográficos, y que el par de necrológicas que se escribieron a su muerte poco informan de sus años de estudiante ${ }^{5}$, basta la lectura de sus obras para comprobar que el liberalismo ético y filantrópico imperante durante el Sexenio en las aulas universitarias, en las Cortes, en el Ateneo, en las tertulias y en la prensa, ejerció un duradero influjo en Santamaría. Dentro de este liberalismo, en parte plasmado en la Constitución de 1869, dos ideas fueron una constante en su pensamiento e incluso en su actividad política, ambas de inequívoco origen krausista: la reforma educativa y la progresiva mejora de las condiciones de vida de las clases sociales más desfavorecidas y (acaso fruto de su condición de huérfano sin fortuna) de los sectores más vulnerables, como las mujeres, los jóvenes y los reclusos.

Comenzó su carrera docente en la Facultad de Derecho de la Universidad de Madrid, tras obtener mediante oposición una plaza de profesor auxiliar en disputa de nuevo con Joaquín Costa ${ }^{6}$. Varias fueron las disciplinas que allí impartió (Derecho Romano, Derecho Político Comparado, Procedimientos judiciales y práctica forense, Filosofía del Derecho y Derecho Internacional) durante los cursos de 1873-1874 y de $1874-1875^{7}$. Este último curso ya bajo la monarquía de Alfonso XII y durante

3 Tipografía del colegio nacional de sordo-mudos y de ciegos, Madrid, 1874.

4 Cfr. C. FERNÁNDEZ-MIRANDA CAMPOAMOR, Vicente Santamaría de Paredes, en M. ${ }^{a}$ del Carmen Bolaños Mejías (coord.) «Juristas y políticos madrileños del siglo xx», Colex, Madrid, 2009, p. 145.

5 Una de ellas, ya citada, es la de Joaquín Sánchez de Toca, presidente a la sazón de la Real Academia de Ciencias Morales y Políticas; la segunda es la que le dedicó Adolfo Posada, Don Vicente Santamaría de Paredes, «Revista de Ciencias Jurídicas y Sociales», año VII, n. ${ }^{\circ}$ 25, enero-marzo de 1924, p. 132-136. La primera tiene muy escaso interés para conocer la vida y la obra de Santamaría, de la que apenas habla a lo largo de sus 30 páginas. La segunda, pese a centrarse en la obra del profesor madrileño, es muy breve.

6 Cfr. C. FERNÁNDEZ-MIRANDA CAMPOAMOR, op. cit. p. 145.

7 De la formación y trayectoria académica (grados, títulos, oposiciones, premios, destinos, etc) de Santamaría, acompañado de un repertorio de sus obra), aparte del citado estudio de C. Fernández-Miranda, se 
un Gobierno presidido por Cánovas, del que formaba parte Manuel Orovio al frente de Fomento (una cartera de la que dependía entonces la Instrucción Pública). Este ministro no dudó en expulsar de sus cátedras universitarias a los mencionados Giner y Azcárate así como a Nicolás Salmerón, por negarse a acatar una orden ministerial que obligaba a adaptar las enseñanzas a los dogmas oficiales de respeto a la Iglesia católica y a la monarquía restaurada. Esa expulsión provocó la dimisión de varios prestigiosos colegas, como Emilio Castelar, Eugenio Montero Ríos, Laureano Figuerola y Segismundo Moret, y conduciría a la fundación en 1876 de la Institución Libre de Enseñanza ${ }^{8}$, cuyo ideario ejercería notable influjo en Santamaría.

En 1875 se licenció en Derecho Administrativo en la misma Universidad de la que ya era profesor auxiliar. Se trataba de una licenciatura entonces distinta de la de Civil y Canónico. Mientras ésta se dirigía al ejercicio de la abogacía, aquélla estaba destinada a los futuros funcionarios. Tres años más tarde se doctoró en Derecho Administrativo (también en la Central, única Universidad capacitada entonces para ello), cuando ya era catedrático de esa disciplina, lo que hoy sin duda nos sorprende.

El 12 de junio de 1876, en efecto, pocos días antes de que entrase en vigor la nueva Constitución, Santamaría ganó por oposición la cátedra de Derecho Político y Administrativo en la Universidad de Valencia, ante un tribunal presidido por Manuel Colmeiro y del que formaba parte, entre otros, Ignacio M. de Ferrán. Tenía tan sólo veintitrés años. Su contrincante fue, una vez más, Joaquín Costa, quien en su diario se lamentaría amargamente de su derrota: « ¡Siempre Santamaría! ¡Por todas partes Santamaría!» ${ }^{9}$. No ha faltado quien sostenga que éste, pese a reunir muchos menos méritos que el polígrafo aragonés, obtuvo esa cátedra gracias a ser yerno del entonces Rector de la Universidad de Valencia, Eduardo Pérez Pujol ${ }^{10}$. Sin entrar en esos pormenores, conviene señalar en honor a la verdad que Pérez Pujol, a la sazón Catedrático de Derecho Civil de esa Universidad, había dejado el rectorado en 1873 , tras haberlo ocupado desde $1869^{11}$. En cualquier caso, las repetidas derrotas académicas de Costa ante Santamaría no fueron óbice para que aquél contase con la colaboración de éste en el libro colectivo Derecho consuetudinario y economía popular

ocupa Y. BLASCO GIL en Vicente Santamaría de Paredes, político y administrativista, en Adela Mora Cañada (coord.), «La enseñanza del derecho en el siglo xx: homenaje a Mariano Peset», Instituto Antonio de Nebrija, 10, Madrid, 2004, pp. 45-80. Tanto C. Fernández-Mirada como Y. Blasco se basan en el expediente personal de Santamaría depositado en el Archivo General de la Administración Pública, sito en Alcalá de Henares. Ese expediente (A. G. A., sig. 32/7285 y sig. 31/16734) lo ha consultado también la profesora C. Álvarez Alonso, a quien agradezco la información que me ha proporcionado al respecto sobre algunos aspectos de la trayectoria académica y administrativa de Santamaría.

8 Sobre este particular, vid. el clásico estudio de V. CACHO VIU, La Institución Libre de Enseñanza. Orígenes y etapa universitaria (1860-1881), Rialp, Madrid, 1962. Muchos más recientemente, VVAA, La Institución Libre de Enseñanza y Francisco Giner de los Ríos. Nuevas perspectivas, Fundación Francisco Giner de los Ríos/ Acción Cultural Española, Madrid, 2013, 3 vols.

9 Cfr. C. FERNÁNDEZ-MIRANDA, op. cit. p. 146, quien recoge la cita de J. J. Gil Cremades.

10 Cfr. S. VALENTÍ CAMP, Ideólogos, teorizantes y videntes, Minerva, Barcelona, 1922. Citado por Carmen Fdez-Miranda, ibídem, p. 146.

11 Sobre la biografía de Pérez Pujol vid. las obras que cita Yolanda Blasco en la nota 31 de su mencionado trabajo. 
en España (Barcelona, 1902), en el que también colaboraron Miguel de Unamuno y Rafael de Altamira, entre otros. Ese mismo año, Santamaría participó asimismo en la encuesta promovida por el Ateneo de Madrid con motivo de la publicación de la influyente obra de Costa Oligarquía y caciquismo como la forma de gobierno actual en España: urgencia y modo de cambiarla (1901) ${ }^{12}$.

En la capital levantina Santamaría desplegó una intensa actividad, tanto académica en el seno de su Facultad, de la que fue secretario, como intelectual a extramuros de ella, con numerosas conferencias en diversas instituciones, especialmente el Ateneo, sobre muy variados asuntos, entre ellos: «La misión social de la mujer», «La biología jurídica», «Examen del positivismo», «Medios prácticos para hacer compatible el orden con la libertad», «Comunidades religiosas» o «Armonía entre las Ciencias y el Arte», además de publicar algún artículo en el diario local «Las Provincias» ${ }^{13}$. En Valencia reforzó la amistad con Eduardo Pérez Pujol, cuyas ideas sociales tuvieron un notable influjo sobre Santamaría, quien por esas mismas fechas no dudaría en autodefinirse como un «liberal armónico» ${ }^{14}$. Las ideas sociales del profesor valenciano, alejadas tanto del liberalismo individualista como del socialismo, y muy próximas a las del krausismo, tenía por objeto mediar entre el capital y el trabajo. Entre ellas destacaban los jurados mixtos, la beneficencia, las casas de socorro y las sociedades cooperativas de producción y consumo, así como la restauración de los gremios ${ }^{15}$. Como se verá más adelante, Pérez Pujol prologaría las dos obras más relevantes de Santamaría, los Cursos de Derecho Político y de Derecho Administrativo, mientras que Santamaría le correspondería prologando una obra póstuma del profesor valenciano: Historia de las instituciones sociales de la España goda ${ }^{16}$.

En noviembre de 1883, sustituyendo al jubilado Colmeiro, se trasladó a la Facultad de Derecho de la Universidad Central, mediante un concurso al que también se había presentado Enrique Gil Robles, Catedrático en Salamanca. Santamaría fue durante varios años Decano de esa Facultad y en ella permaneció hasta su jubilación el 22 de octubre de 1920. Ese año fue sustituido por Adolfo Posada, quien estuvo al frente de la mencionada cátedra hasta $1934^{17}$. Se encadenaban, así, los tres tratadistas del Derecho Público español más influyentes desde la segunda mitad del siglo XIX hasta la II República: Colmeiro, Santamaría y Posada. Una influencia en parte simultánea, pero sobre todo sucesiva.

12 Cfr. C. FERNÁNDEZ-MIRANDA, op. cit. p. 146.

13 Cfr. Y. BLASCO, op. cit. p. 80, nota 72.

14 «Los socialistas sólo ven el todo, los individualistas las partes; nosotros, el todo y las partes, en su relación armónica», Curso de Derecho Político, $4 .^{a}$ edición (por la que se citará en adelante), Establecimiento tipográfico de Ricardo Fe, Madrid, 1890, p. 10. Hay una edición facsimilar en Analecta, Pamplona, 2004.

15 M. SUÁREZ CORTINA contextualiza esas ideas en Republicanismo y nuevo liberalismo en la España del novecientos, dentro de la obra colectiva, coordinada por este autor, Las máscaras de la libertad. El liberalismo español. 1808-1950, Marcial Pons Historia, Madrid, 2003, especialmente pp. 336, 338 y 353.

16 Valencia, 1886.

17 Cfr. A. G. POSADA, Fragmentos de mis Memorias, Servicio de Publicaciones de la Universidad de Oviedo, Oviedo, 1983, pp. 344-5. 


\section{EL CURSO DE DERECHO POLÍTICO Y OTROS ESCRITOS JURÍDICOS Y SOCIOLÓGICOS}

La asignatura «Elementos de Derecho Político y Administrativo», cuyo creador había sido Colmeiro ${ }^{18}$, se introdujo en las Facultades de Derecho por obra del plan de estudios de 1857, auspiciado por Claudio Moyano, que se mantuvo en vigor hasta 1900. Año en el que un nuevo plan, promovido por Antonio García Alix, separaría ambas disciplinas, creando la asignatura de «Derecho Político comparado con el extranjero» y obligando a cotejar las instituciones españolas con las extranjeras más relevantes ${ }^{19}$, lo que no contribuía, desde luego, a sistematizar e interpretar el ordenamiento vigente desde sus propias entrañas, como veremos más adelante.

Fruto de esa dualidad de intereses, Santamaría redactó sendos Cursos de Derecho Político y de Derecho Administrativo. El primero de ellos, de casi novecientas páginas llevaba por título: Curso de derecho político, según la filosofía política moderna, la historia general de España y la legislación vigente». La primera edición vio la luz en 1880-1881, en Valencia. Se reeditó, ya en Madrid, en 1883, 1887, 1890, 1893, 1898, 1903, 1909 y 1913. Pero, en realidad, desde 1890 se trataba más bien de reimpresiones, pues las novedades son poco relevantes ${ }^{20}$.

En 1882 la Dirección General de Instrucción Pública, dependiente de José Luis Albareda, a la sazón ministro de Fomento en un Gobierno presidido por Sagasta, declaró que debía servir a su autor de «mérito especial» en su carrera. Una declaración que desde 1883 se recogía en todas las ediciones de esta obra, en las que también se hacía constar que había sido objeto de varios artículos en «importantes revistas españolas y extranjeras», entre ellas uno de Mr. Maurice Block, «el más conocido y uno de los más reputados publicistas de Europa en ciencias políticas», que se reproducía íntegramente, pese a su tono paternalista y engreído. Tras señalar que, «quoique babitant à l'extremité de l'Europe», Santamaría «est au courant des discus-

18 Lo reconocería el propio Posada en la obra citada en la nota anterior, p. 345. Por su parte, Alfredo Gallego Anabitarte, refiriéndose a los Elementos de Derecho Político y Administrativo de España, cuya primera edición vio la luz en 1858 y la séptima en 1887, escribe: «Los «Elementos» de Colmeiro fue el libro con el que empezaban y terminaban los estudios políticos y administrativos los estudiantes de Derecho durante gran parte del siglo XIX», Las asignaturas de Derecho Político y Administrativo: el destino del Derecho Público Español, «Revista de Administración Pública», n. ${ }^{\circ}$ 100-102, vol. I, enero-diciembre de 1983, pp. 756-757.

19 Así lo establecía el Real Decreto de 1 de agosto de 1900, publicado tres días más tarde en la «Gaceta». Sobre este particular, vid. Manuel Martínez Neira, El estudio del derecho. Libros de texto y planes de estudio en la Universidad contemporánea, Universidad Carlos III/ Dykinson, Madrid, 2001.

20 El Índice o «Plan General de la obra» permanece, en efecto, inalterado desde la cuarta edición. Sólo en el capítulo XVII ( «España Constitucional») de la parte dedicada a la «Historia del Derecho Político Español» se actualizan, en muy breves líneas, lo dicho en relación al reinado de Alfonso XII, a la Regencia de M. ${ }^{a}$ Cristina y, desde 1902, al reinado de Alfonso XIII. Se introducen también muy ligeras actualizaciones en la sección segunda (Legislación política especial), en la parte dedicada a la «Legislación política vigente en España», en lo relativo a la Ley de Asociaciones y sobre todo a la Ley Electoral del Congreso, tras la aprobación del sufragio universal masculino el 26 de junio de 1890. Por último, a partir de la séptima edición (1903) se inserta un apéndice sobre «Legislación Extranjera Vigente» «para facilitar el estudio comparado del Derecho Político Español con el extranjero» y se pone al día el apéndice relativo a los «Gobiernos Españoles desde el año 1833» y a las «Cortes Españolas desde el año 1834». 
sions qui ont eu lieu dans les grands centres littéraires et scientifiques du nord et de l'ouest de notre continent», el hoy olvidado Mr. Block reconocía que el profesor español era «un savant de beaucoup de mérite», que su libro, más allá de sus discrepancias, «fait reflechir» y que el tema que trataba era «des plus attachants».

Mayor interés tiene el extenso, erudito y elogioso prólogo del ya citado Eduardo Pérez Pujol, aunque resulte más instructivo para conocer el pensamiento del prologuista que el del prologado, por otro lado coincidentes en lo esencial, como confiesa el profesor valenciano, quien, sin embargo, añade: «... Lo que en mi han sido conceptos incompletos, atisbos pasajeros, forma en el Curso de Derecho Político un sistema completo, un conjunto orgánico» ${ }^{21}$. Al final de su prólogo Pérez Pujol sostenía que, sin perjuicio de buscar siempre la objetividad exigible a una obra científica, el Curso no dejaba de proclamar unas ideas políticas incompatibles con «el federalismo, el ultramontanismo, el anarquismo y el despotismo, el doctrinarismo, en cuanto es una transacción arbitraria entre la revolución y la reacción, y el socialismo en todas sus fases». En cambio, el Curso podía «ser aceptado como ideal por los partidos conservador y progresivo, que sólo difieren en las cuestiones de tiempo y de oportunidad», al armonizar en «la vida política la libertad y el orden, la conservación y el progreso» ${ }^{22}$.

Santamaría de Paredes dedica los tres primeros capítulos introductorios de su Curso de Derecho Político a definir esta rama del saber. En esta trascendental cuestión resulta decisivo el influjo del krausismo. Un movimiento de ideas cuya influencia en la cultura española de la segunda mitad del siglo xIx fue, como es bien sabido, enorme, sobremanera en el campo de la Filosofía del Derecho y, a partir de ella, en el Derecho Político ${ }^{23}$ y del que Santamaría fue un correligionario bastante heterodoxo. Siguiendo la concepción tripartita de esta disciplina que habían defendido los krausistas y muy en particular Ahrens, Santamaría de Paredes, según se ha visto, subtitula su Curso de Derecho Político de manera muy reveladora: «según la filosofía política moderna, la historia general de España y la legislación vigente».

A su juicio, las palabras derecho político «en su acepción más lata, equivalen a derecho público y comprenden, como es consiguiente, la existencia y vida entera del Estado; pero en su acepción más restringida, significan tan sólo una parte o rama del derecho público, empleándose usualmente en equivalencia a derecho constitucional» ${ }^{24}$.

Con el objeto de determinar el concepto de derecho político en este último sentido, Santamaría ahonda en el concepto de Constitución, a la que define como «la organización fundamental del Estado. Esta Constitución, prosigue, establece el

21 Curso de Derecho Político, op. cit. p. 19.

22 Ibídem, pp. 52 y 54.

$23 \mathrm{Al}$ influjo del krausismo, sobremanera de Ahrens, en el Derecho Político español dedico unas cuantas páginas en mi trabajo ¿Qué ocurrió con la Ciencia del Derecho Político en la España del siglo XIX?, que recojo en mi libro recopilatorio Política y Constitución en España. 1808-1978, CEPC, Madrid, 2. edición, 2014, prólogo de F. Rubio Llorente.

24 Curso de Derecho Político, op. cit. p. 72. 
organismo de los poderes, regula el ejercicio de las funciones públicas, y determina el genio e índole de los pueblos, a la manera como la constitución moral y fisiológica determina también el carácter y temperamento de los individuos. Considerando, pues, el derecho político en la acepción estricta a que antes nos referíamos, será el derecho que determina la naturaleza y organización fundamental del Estado» ${ }^{25}$.

Ahora bien, así definido el derecho político, ¿cuál es el método que debe seguir la Ciencia que lo estudia? Santamaría responde a esta pregunta señalando que el Derecho Político como ciencia tenía una triple vertiente, histórica, filosófica y filosófico-histórica, de la que se ocupaban tres saberes distintos. La «Filosofía del Derecho Político» tenía por objeto el estudio de «los principios políticos comunes a todos los lugares, a todas las épocas y a todos los pueblos», extraídos de la razón ${ }^{26}$. De una razón, claro es, natural, ahistórica. A la «Historia del Derecho Político» correspondía examinar las instituciones políticas específicas de cada Nación, así como de su derecho positivo, tanto del pasado como del presente, pues, a su entender, «el llamado «Derecho vigente» es sólo el «Derecho positivo» de la época en que se vive y aparece como última página de la Historia, pero sin dejar de ser conocimiento histórico» ${ }^{27}$. Una afirmación sin duda muy ilustrativa. Por último, señalaba Santamaría, «el Derecho Político debía echar mano de una tercera ciencia, la «filosóficohistórica del Derecho Político», encargada de estudiar «a la vez el principio y el hecho en su íntima relación», esto es, la organización ideal o racional del Estado y su organización positiva, histórica. Una Ciencia que, a su vez, se dividía en dos: la «Crítica de las leyes e instituciones» y la «Nomotesia» o «Reforma Legislativa» ${ }^{28}$.

Conforme a estas premisas, tan fieles a las que Ahrens había sustentado, el «Curso» de Santamaría se divide en tres partes: «Principios Generales del Derecho Político», «Historia del Derecho Político Español»y «Legislación Política Vigente». La primera es la más amplia, pues en el estudio del Derecho Político era preciso dar «mayor extensión a la filosofía que a la Historia, porque tratándose de un Derecho nuevo, son más útiles las enseñanzas de la moderna ciencia que la narración de los hechos antiguos» ${ }^{29}$. Pero además de su mayor amplitud, esta parte es con mucha diferencia la más interesante y alada de las tres. En ella su autor se ocupa de la Filosofía Política o, con más exactitud, de lo que hoy llamaríamos Teoría del Estado, poniéndose de manifiesto su deuda con Hegel, Krause, Ahrens y los krausistas españoles, sobremanera Giner de los Ríos y Gumersindo de Azcárate, pero también con el suizo Johanmes Caspar Bluntschli. Un autor que gozó de notable predicamento entre los tratadistas españoles del último tercio del siglo xIX y cuyas dos obras clave se habían traducido del alemán al francés, con el título La Theorie Gènèrale de l'Etat y La Politique, ambas en la parisina Librairie Guillanmin, en 1877 y 1878, respectivamente, mientras que en 1880 se publicó en Madrid, en tres volúmenes, su Derecho

\footnotetext{
25 Ibidem, p. 74, cursiva del autor.

26 Ibidem, p. 75

27 Ibídem, p. 76

28 Ibidem, p. 76

29 Ibídem, p. 79
} 
Público universal ${ }^{30}$. Spencer fue también un autor muy influyente en la concepción del Estado (y de la nación) que sostiene Santamaría ${ }^{31}$.

Para Santamaría, el Estado era «la Sociedad organizada para declarar el Derecho de un modo supremo e inapelable, cumplirle en relación con todos los fines de la vida y hacerle cumplir por la coacción cuando no se realice voluntariamente» ${ }^{32}$. Una definición discordante con la ortodoxia krausista (que en el ámbito del Derecho Político español sustentaría Posada), al resaltar más la coacción que la persuasión en el cumplimiento de Derecho. Un extremo en el que coincidía con Pérez Pujol $^{33}$ y en el que insistiría el profesor madrileño en su discurso de contestación a la recepción de Antonio López Muñoz en la Real Academia de Ciencias Morales y Políticas. En esta ocasión, de manera tan explícita como respetuosa, Santamaría se separaba de Krause y sobre todo de Giner, a la par que se aproximaba a las tesis de los neokantianos Ihering, Korkounow, Stamler, Natorp y, sobre todo, Jellinek ${ }^{34}$.

En esta primera parte del «Curso», su autor examina los elementos, los medios y los fines del Estado, sus relaciones con el individuo y con la sociedad, también con la Iglesia, con una interesante reflexión sobre los derechos y deberes. Dedica un buen número de páginas a describir la organización y funcionamiento del Estado y las formas que éste revestía, desde una inequívoca crítica al federalismo, sobremanera cuando se partía de un Estado nacional previamente unido políticamente ${ }^{35}$ (el recuerdo de la España de 1873, a la que no cita, pesaba lo suyo). Termina sus reflexiones sobre el Estado con unas observaciones sobre su vida política «normal» (nacimiento, crecimiento, decadencia y muerte), y «anormal» (anarquía, despotismo, golpes de Estado y revoluciones).

El examen de estas cuestiones es muchas veces brillante e incluso no exento de cierta originalidad, como ocurre cuando se extiende sobre la Jefatura del Estado como «poder armónico» ${ }^{36}$.

La segunda parte del Curso que ahora se comenta es un compendio, de alrededor de doscientas páginas, de Historia Política de España, desde la «primitiva y

30 Sobre el contexto histórico e intelectual en el que Bluntschli escribe, vid. O. MEUWLY, Les penseurs politiques du $19 e$ siècle. Les combats d'idées à l'origine de la Suisse moderne, Presses polytecniques et universitaires romandes, Lausanne, 2007, pp. 61 y ss.

31 En esta influencia insiste I. Iriarte López en su estudio preliminar a los Escritos Políticos de Gregorio de Balparda, Universidad del País Vasco, Bilbao, 2013, p. 32. En las pp. 31 a 25 Iriarte pone de relieve el enorme influjo de Santamaría en el pensamiento político de Balparda.

32 Curso de Derecho Político, op. cit. p. 98.

33 Cfr. ibidem, p. 18.

34 Cfr. La Política y la Moral, op. cit, pp. 68 a 81.

35 Curso de Derecho Político, op. cit. pp. 388-389 y 407-408. En el antifederalismo de Santamaría insiste Pérez Pujol en la p. 24

36 Á. MENÉNDEZ REXACH llega a sostener que «en la construcción de Santamaría de Paredes aparecen todos los problemas que todavía hoy gravitan en torno a la Jefatura del Estado», La Jefatura del Estado en el Derecho Público Español, Instituto Nacional de la Administración Pública, Madrid, 1979, pp. 209. Llevo a cabo un análisis de esta cuestión en Santamaría de Paredes y el Derecho Político de la Restauración, incluido en mi citado libro recopilatorio Política y Constitución en España. 1808-1978. En general examino aquí con más amplitud que ahora el contenido de su Curso de Derecho Político. 
romana» hasta la «constitucional», pasando por la «goda», la «musulmana», la de los diversos reinos cristianos medievales y la de la «Monarquía nacional y absoluta» de los Reyes Católicos, los Austrias y los Borbones. Lo primero que cabe subrayar de este apretado recorrido histórico (del que sólo cabe destacar su esfuerzo de síntesis y la claridad de su exposición, común a todo el Curso, como queda dicho), es que el concepto de España, al retrotraerlo a tan remotos tiempos, se utiliza de forma anacrónica. Lo mismo había hecho antes Colmeiro en sus mencionados «Elementos de Derecho Político y Administrativo» (1858) y en su «Curso de Derecho Político, según la historia de León y Castilla» (1873), al estudiar las instituciones políticas básicas de la Constitución histórica de España, esto es, la Corona y las Cortes, desde la invasión goda ${ }^{37}$.

Con este concepto de «España», Santamaría de Paredes, como antes Colmeiro, no hacían más que continuar los patrones del nacionalismo historiográfico español, cuyo fruto más acabado por aquellos años era la Historia General de España, de Modesto Lafuente, compuesta de treinta volúmenes, que se fueron publicando entre 1850 y 1867, y que a partir de 1887 continuarían Juan Valera, Andrés Borrego y Antonio Pirala. Una obra que, en realidad, sirvió de referencia a la historiografía española hasta la Segunda República ${ }^{38}$.

Si nos centramos tan sólo en la última etapa de su recorrido histórico, la «España Constitucional», que se inicia en 1808, la verdad es que su interés es muy escaso. Sólo quince páginas dedica Santamaría a describir, no más, los avatares del constitucionalismo histórico español desde la invasión napoleónica hasta el reinado de Alfonso XII (límite que, como se ha adelantado ya, fue ampliando en las sucesivas ediciones de su Curso). Sin citar fuente directa alguna, el único historiador que menciona, aunque omita referirse a una obra en concreto, es Juan Rico y Amat, con quien se inaugura lo que ya puede denominarse con propiedad historia política de la España liberal, como ha señalado recientemente Ignacio Fernández Sarasola ${ }^{39}$. Rico y Amat, en efecto, narra las vicisitudes políticas de la primera mitad del XIX en su Historia política y parlamentaria de España, desde los tiempos primitivos hasta nuestros días: escrita y dedicada a S. M. la Reina Doña Isabel II, publicada en Madrid entre 1860 y 1861, y rescata la memoria de los diputados de las distintas Cortes constitucionales en El libro de los diputados y senadores: juicios críticos de los oradores más notables desde la cortes de Cádiz hasta nuestros días, con la inserción integra del mejor discurso que cada uno de ellos ha pronunciado, que vio la luz en la capital de España entre 1862 y 1866.

37 Aunque, como recuerda Pérez Pujol, Colmeiro se habían circunscrito a los reinos de Castilla y León, mientras que Santamaría ofrecía en su Curso «por primera vez en España» una exposición completa de las instituciones políticas de España en todos los reinos de la Península, «bajo el concepto de la unidad superior que constituye nuestro carácter nacional», Ibídem, p. 44.

38 Sobre esta obra se extiende J. ÁLVAREZ JUNCO en su reciente libro, escrito en colaboración con G. DE LA FUENTE, C. BOYD y E. BAKER, Las historias de España. Visiones del pasado y construcción de identidad, Crítica/Marcial Pons, Barcelona, 2013, pp. 263 y ss.

39 Aproximación a la historiografía constitucional española, en J. VARELA SUANZES-CARPEGNA (ed.) «Historia e Historiografía Constitucionales», Trotta, Madrid, 2014. 
De la Constitución de 1876 se ocupa Santamaría en la tercera y última parte del «Curso», que se divide en dos secciones: la que examina «la Constitución política vigente comparada con las anteriores», y la que analiza la «Legislación política especial», que también fue variando en las sucesivas ediciones de esta obra. Al estudio de la primera le dedica unas 90 páginas de un libro de casi novecientas, es decir, la décima parte. Y aun así «comparada con las anteriores». Una comparación, por añadidura, sin apenas atractivo, al basarse exclusivamente en el cotejo, precepto a precepto, de la Constitución canovista con los textos constitucionales vigentes desde el Estatuto de Bayona.

Dentro de estos textos, Santamaría distingue una «parte dogmática» y otra "parte orgánica». Distinción implícita en Colmeiro y que tendría gran fortuna en el Derecho Político español ${ }^{40}$. A la parte dogmática dedica Santamaría un capítulo, en el que se examinan «los españoles y sus derechos», mientras que a la parte orgánica se consagran cuatro capítulos, que versan sobre las Cortes, el Rey, los Ministros y la Administración de Justicia.

En lo que atañe a la sección relativa a la legislación política especial, Santamaría analiza, de manera puramente descriptiva, algunas leyes de especial relevancia para el ejercicio de los derechos reconocidos en la Constitución y para la organización de los poderes del Estado, como la Ley de Policía e Imprenta, la Ley de Reuniones Públicas, la Ley de Asociaciones, las Leyes Electorales del Congreso y del Senado y la Ley de relaciones entre los Cuerpos Colegisladores.

En sus Memorias, escritas después de la Guerra Civil, Posada recuerda que en torno a 1892 su editor, Victoriano Súarez, le animó a escribir un Tratado de Derecho Político (cosa que haría al año siguiente) con estas palabras: «Nadie mejor que usted. Haga un Derecho Político. «El Santamaría» se ha vendido muchísimo y se sigue vendiendo, pero oigo decir que está pasado. No sé lo que quieren, pero quieren otro libro. Un Manual o Tratado de Derecho Político caería ahora muy bien» ${ }^{41}$.

En esta misma obra Posada califica de «excelente» el «Curso» de Santamaría de Paredes (también el de Derecho Administrativo, del que hablaremos más tarde), aunque considere que era un tanto anticuado. Escuchémosle:

«El Derecho Político de Santamaría señala un momento muy definido de la evolución de esta enseñanza típicamente española por su misma denominación de derecho político, y no derecho público (el Droit Public francés). El libro de Santamaría aparece en el momento del máximo apogeo del influjo de Ahrens combinado con el de Bluntschli, especialmente por su Teoría general del Estado. Pero Santamaría cristalizó el Derecho Político en su Tratado sin advertir las nuevas tendencias.» ${ }^{42}$.

40 Posada recuerda que la distinción entre la parte dogmatica y la orgánica de las Constituciones, que él también acoge, la tomó del «Derecho Natural» de Giner, pero que éste parecía habérsela oído «al Sr. Figuerola cuando explicaba en su cátedra de Derecho Político Comparado». Tratado de Derecho Político, Madrid, 1894, vol. II, p. 14, nota 1. Pero, en rigor, como queda dicho, creo que esta distinción debe atribuirse a Colmeiro.

41 Fragmentos de mis Memorias, op. cit., p. 277.

42 Ibidem, p. 345. 
Este último comentario crítico, al que con otras palabras ya se había referido el mencionado Victoriano Súarez, no carecía de fundamento y con el tiempo lo tendría todavía más, pues, como queda dicho, Santamaría no modificó más que en aspectos de escasa relevancia, ni siquiera en 1913, año de su última edición, lo que había sustentando en la primera, escrita treinta y tres años antes.

Ello no impidió que su «Curso de Derecho Político» tuviese un gran éxito, como lo prueban sus nueve ediciones. El propio Posada, en la necrológica que le dedicó a su autor en 1924, recuerda que ese Curso, además de ser su obra «más importante y característica», fue también la más difundida.

«Entre los hombres de estudio y de las profesiones del Derecho, cuando se dice «el Santamaría», todos entienden: se alude al Curso de Derecho Político, tan leído por las juventudes de las Facultades de Derecho de España y de la América española y tan estudiado para preparar los programas en las oposiciones a las diversas profesiones especiales, jurídicas y de la Administración pública» ${ }^{43}$.

Este éxito se explica en buena medida por la mesura política y el espíritu conciliador con el que su autor redactó su Curso, con el que podían identificarse los seguidores de los dos partidos dinásticos que desde 1876 hasta 1923 se repartieron el poder en España, como venía a señalar Pérez Pujol en su comentado prólogo (que Posada califica de «magistral» $\left.{ }^{44}\right)$. El propio Santamaría recalca su firme intención de mantenerse alejado de la esfera de los partidos políticos ${ }^{45}$. Pero en este éxito tuvo también mucho que ver el afán sistemático, la concisión y claridad con la que está redactado su Curso, con pocas citas y sin apenas notas a pie de página, e incluso su buen estilo literario, sobrio y elegante. El mismo Posada, refiriéndose en general a todos sus escritos e incluso a sus clases y discursos, señaló que Santamaría «tenía como pocos el arte de exponer de palabra o por escrito, clara y sencillamente, las ideas y conceptos en las materias de su especialidad. Era esa, quizá, su nota más saliente como tratadista y como profesor: la claridad en la exposición. Como orador académico, su palabra fácil servía siempre a un pensar y a un razonar claros» ${ }^{46}$.

Por su parte, Joaquín Sánchez de Toca, destacado miembro del Partido Conservador, exministro, teórico del parlamentarismo y compañero de Santamaría (y de Posada) en la Real Academia de Ciencias Morales y Políticas, en otra necrológica escrita ese mismo año señalaba que todos los que habían sido alumnos suyos «rindieron unánime testimonio de que sus exposiciones eran modelo clásico, singularmente por la claridad y estructura de su exposición metódica. Eso mismo descuella como característica suya en sus variadísimos escritos» ${ }^{47}$.

43 Don Vicente Santamaría de Paredes, op. cit., p. 133.

44 Ibidem, p. 134. Posada añade que Pérez Pujol fue «una de las grandes figuras del profesorado universitario de España y que tanto influyó en la formación científica de Santamaría»-

45 Ibidem, p. 78. Y ello por cuanto dentro del Derecho Político en el Curso se trataba de exponer su «Ciencia» y no su «Arte», ibídem, pp. 77-78.

46 Ibídem, p. 135.

47 J. SÁNCHEZ DE TOCA, op. cit., p. 8 
Dos autores posteriores muy dispares, Francisco Rubio Llorente y Francisco Elías de Tejada, coinciden en poner de relieve esa cualidad, tan escasa y tan valiosa entonces como ahora. Si para el primero Santamaría fue «tal vez la mente más clara de nuestros constitucionalistas decimonónicos y desde luego el más legible» ${ }^{48}$, para el segundo el «Curso de Derecho Político» de Santamaría era «el más claro y didáctico de cuantos nacionales o extranjeros han caído en mis manos hasta ahora» ${ }^{49}$.

Esas cualidades se perciben también en el Curso de Derecho Administrativo, según sus principios generales y la legislación actual de España, cuya primera edición es de 1885 mientras que la octava y última es de $1914^{50}$. Todas ellas venían precedidas también de un extenso prólogo a cargo de Eduardo Pérez Pujol. Aunque, como señala el prologuista, este Curso y el anterior formen «un conjunto armónico, mejor dicho, un verdadero todo orgánico ${ }^{51}$, las diferencias de enfoque entre uno y otro son notables. Ahora se prescinde de la historia, pese a extenderse sobre los precedentes de la institución ministerial, de los gobernadores civiles o de la legislación y organización penitenciarias, por citar algunos ejemplos ${ }^{52}$. Es además una obra mucho menos filosófica, más técnica, que se centra, como señala su subtítulo, en los principios generales y en la legislación vigente (también en menor medida en la doctrina y la jurisprudencia) pero conectando ambos extremos. Cosa que no hace en el Curso de Derecho Político, en demérito de éste. Veamos las razones que aduce su autor:

«Si en el Derecho Político hemos separado la Filosofía, la Historia y la Legislación vigente, por no concordarse en un mismo cuadro de instituciones, entendemos que habiendo de exponerse dogmáticamente el Derecho administrativo según un plan racional y dado el carácter positivo de su enseñanza, pueden aparecer unidos estos tres aspectos en cada institución u orden de instituciones, estableciendo primero sus principios generales, luego sus antecedentes históricos, y por último, su legislación actual, que ha de ser la parte más extensa.» ${ }^{53}$.

Santamaría define el Derecho Administrativo como «la rama del Derecho referente a la organización, funciones y procedimientos del poder ejecutivo, según la

48 Nota preliminar a la edición española del «Derecho Político» de E. STEIN, Aguilar, Madrid, 1973, p. XIII.

49 Derecho Político, en «Nueva Enciclopedia Jurídica Seix», Barcelona, 1975, vol. I, p. 904.

50 Entre una y otra fecha se editó en 1888, 1891, 1894, 1898, 1903 y 1911. Aquí se ha consultado la octava y última edición, Imprenta Española, Madrid, 1914. La preparación de esta obra era bastante anterior. A este respecto, en su expediente académico consta que por Real Orden de 1 de marzo de 1882, el rey le concedió permiso para residir en Madrid con el fin de escribir una obra sobre Derecho administrativo y viajar al extranjero para «visitar los archivos y bibliotecas». Consta, asimismo, que el 22 de septiembre de 1882 Santamaría solicitó al Ministerio de Fomento, y este aceptó al día siguiente, prorrogar dos meses la comisión que se le había confiado por la mencionada Real Orden de 1 de marzo, a fin de terminar su investigación sobre derecho administrativo. No hay constancia, sin embargo, del destino de ese viaje de estudios.

51 Curso de Derecho Administrativo, op. cit., p. 1.

52 Ibidem, pp. 140 y ss., pp. 163 y ss. y pp. 295 y ss.

53 Ibidem, pp. 45-46. 
Constitución, para el cumplimiento de la misión del Estado en la vida» ${ }^{54}$. Una definición que, como subrayaba Pérez Pujol, implicaba reducir «el Derecho Administrativo a mera rama derivada del Derecho Político, contradiciendo la opinión corriente que los consideraba como dos ramas hermanas nacidas del tronco común del Derecho Público ${ }^{55}$. Insistía, en efecto, Santamaría en que su Curso de Derecho Administrativo era el desarrollo del anterior sobre el Derecho Político, muy en particular en lo relativo al capítulo dedicado allí al poder ejecutivo y en lo concerniente a las doctrinas sobre los fines y medios del Estado. «Decimos esto para advertir que, siendo, a nuestro entender, el Derecho Administrativo una rama del Derecho Político, que por su frondosidad aparece como árbol separado en la Enciclopedia jurídica, tomamos como punto de partida dicha obra» ${ }^{56}$, esto es, el Curso de Derecho Político. Por otro lado, insistía Santamaría en no «confundir la Ciencia del Derecho administrativo con la Ciencia de la Administración, ni tampoco separarlas arbitrariamente». Mientras la primera comprendía todas las ciencias que se ocupaban de la Administración, la segunda sólo consideraba a ésta en su aspecto jurídico ${ }^{57}$.

A partir de estas premisas y tras unas reflexiones preliminares sobre el concepto, relaciones, fuentes y método del Derecho Administrativo, el profesor madrileño divide su Curso en tres partes. Una primera relativa a la «organización administrativa», tanto en general como en especial, examinando la Administración central, la provincial y la municipal, con un apéndice muy esquemático con los modelos vigentes sobre estos asuntos en varios países europeos. Una segunda parte, la más extensa, dedicada a las «funciones administrativas», tanto en lo concerniente a los fines del Estado, como a sus medios, y a las relaciones entre unos y otros. Una tercera, la más breve, se ocupa del «procedimiento administrativo», tanto del gubernativo, como del contencioso, así como de las competencias.

Aunque no procede aquí extenderse sobre el contenido de esta obra, si es preciso señalar que supuso un notable avance en la conformación del Derecho Administrativo español respecto de los anteriores estudios de Colmeiro y por supuesto de los cultivadores de la Ciencia de la Administración durante la primera mitad del siglo XIX, como Javier de Burgos, Alejandro Oliván, Mariano Ortiz de Zúñiga, Pedro Gómez de la Serna, José de Posada Herrera y Fernando Cos-Gayón.

Las dos obras principales de Santamaría de Paredes fueron sin duda alguna los dos Cursos que se acaban de comentar (sobre todo el primero, aunque éste haya envejecido peor que el segundo), perfilados de forma casi definitiva entre 1880 y 1885 , sin duda sus años más productivos desde un punto de vista científico. Pero lejos de la especialización que caracterizaría a los juristas posteriores, Santamaría publicó antes y después de esos años, varias obras sobre otras ramas del Derecho, como unos Principios del Derecho Penal, con aplicación al código español (Madrid, 1871

54 Ibídem, p. 38.

55 Ibídem, p. 3.

56 Ibidem, p 33.

57 Ibídem, p. 39 
y 1872), escritos cuando no había cumplido los $20 \mathrm{años}^{58}$. Tampoco le fueron ajenas las cuestiones de Derecho Internacional Público, como lo prueba su Estudio de la cuestión de límites entre las Repúblicas del Perú y del Ecuador, que vio la luz en 1907.

Incluso dio a la imprenta varios escritos ajenos al Derecho, en los que se ponían de relieve su atenta lectura de los más reputados tratadistas de la pujante Sociología, sobre todo alemanes, como Häckel o Schäffle (casi siempre citados en lengua francesa), pero también franceses, empezando por Comte, algún británico, sobremanera Spencer, y, entre los españoles, Sales Ferré, Gumersindo de Azcárate y el mencionado Pérez Pujol, sin duda hitos fundamentales en la articulación de la moderna Sociología española, tras las precedentes aportaciones de un Balmes o de un Ramón de la Sagra. Entre sus trabajos de carácter sociológico destacan El concepto de organismo social (Madrid, 1896) y El concepto de sociedad, discurso leído en la Universidad Central con motivo de la inauguración del curso académico de 1901 a 1902, en el que Santamaría confesaba expresamente su preocupación, incluso podríamos decir su obsesión, por «la claridad de ideas» y por la «precisión del lenguaje» al transitar por, a veces, tan áridas materias ${ }^{59}$.

\section{PARLAMENTARIO, MINISTRO Y PRECEPTOR REGIO}

La faceta más relevante de su vida fue la de profesor universitario, en su doble dimensión docente e investigadora. Esa faceta fue la que el propio Santamaría valoró por encima de cualquiera otra de sus actividades ${ }^{60}$, entre las que se encontraban la abogacía ${ }^{61}$ y la política. A esta última dedicó parte de su tiempo, sobre todo entre 1886 y 1906, esto es, cuando su producción científica disminuye, tras la redacción de los dos comentados Cursos. Miembro del Partido Liberal, inició su carrera política como diputado por Cuenca en la legislatura de 1886, repitiendo escaño en las de 1893 y 1898. Desde marzo de 1889 a julio de 1890 fue Director General de Instrucción Pública. En 1901 fue elegido senador, con la consideración de vitalicio desde 1903. El 1 de diciembre de 1905 fue nombrado ministro de Instrucción Pública y Bellas Artes en un Gobierno presidido por Segismundo Moret. Pero sólo permaneció en el cargo hasta el 10 de junio de 1906. Pocos días después, el 6 de julio, dimitiría el propio Moret, falto de apoyo parlamentario y con su prestigio muy menoscabado, incluso entre los miembros de su propio partido, tras el atentado que el 31 de mayo había sufrido Alfonso XIII a manos del anarquista Mateo del Morral, que provocó una veintena de muertos, y por haber alentado la aprobación en marzo de ese mismo año de la «Ley de Jurisdicciones», bajo la presión del Rey y

58 Junto a L. VILLARRAZO publicó también un Curso de Derecho Penal Español en 1871.

59 Imprenta Colonial, Madrid, 1901, p. 11.

60 Insiste en este extremo Posada en su citada necrológica, p. 132.

61 Fue abogado del Ilustre Colegio de Madrid desde mayo de 1874 y es autor de un trabajo titulado La profesión de abogado en general y en España, recogido en el «Diccionario de Legislación Española», dirigido por Mas y Abad, como consta en su expediente personal. 
del Ejército. Algunos de cuyos miembros habían asaltado en Barcelona un año antes las redacciones de «La Veu de Catalunya» y de «El Cu-Cut». Un triste episodio que había provocado la dimisión de Montero Ríos, su adversario en el seno del Partido Liberal y su predecesor en la jefatura del Consejo de Ministros ${ }^{62}$.

Dentro de la actividad parlamentaria de Santamaría de Paredes conviene destacar dos importante iniciativas legislativas. La primera, bajo un Gobierno presidido por Sagasta, es la ley que reformó la jurisdicción contencioso-administrativa el 13 de septiembre de 1888. Hasta entonces esa jurisdicción se había atribuido en exclusiva al Consejo de Estado. A partir de ese año tal jurisdicción, de acuerdo con un sistema mixto, se atribuyó a un tribunal de lo contencioso administrativo en el seno del Consejo de Estado, formado por miembros de este órgano y por jueces. Santamaría fue el impulsor de esa ley, que no en vano lleva su nombre, aunque el resultado final se alejaba de lo que él había defendido. Pese a sus limitaciones, esa ley supuso un importante avance en el desarrollo del Estado de Derecho en España. Sobre todo cuando, a partir de la reforma de 1904, llevada a cabo por Antonio Maura, esa jurisdicción se atribuyó a la Sala Tercera del Tribunal Supremo y a las Salas de lo contencioso-administrativo de las Audiencias Provinciales, lo que implicaba someter la actividad de la Administración Pública al control de unos tribunales independientes y convertir al Consejo de Estado en un órgano exclusivamente consultivo ${ }^{63}$.

Otra importante iniciativa de Santamaría fue el proyecto de ley que presentó el 25 de diciembre de 1905, apenas recién llegado al ministerio, para fortalecer la autonomía universitaria y la libertad de cátedra. A diferencia de la anterior, esta iniciativa no llegó a buen puerto, como ya había sucedido antes con otras similares auspiciadas por Rafael M. ${ }^{a}$ de Labra, Azcárate y Salmerón ${ }^{64}$. Tampoco tuvo éxito la reforma del artículo 11 de la Constitución de 1876, propuesta por Moret en 1906 con el propósito de ampliar la libertad religiosa.

Libertad de cátedra y libertad religiosa eran dos premisas básicas para los hombres vinculados a la Institución Libre de Enseñanza, quienes en 1907 consiguieron, en cambio, que se pusiese en marcha la Junta de Ampliación de Estudios, que tan gran influjo habría de tener en el desarrollo de la ciencia española y de cuyo primer Consejo formó parte Santamaría de Paredes. Su constante preocupación por

62 Esa ley castigaba con la pena de prisión correccional a los que de palabra o por escrito injuriasen u ofendiesen «clara o encubiertamente» al Ejército, a la Armada, a la nación y a sus símbolos, además de atribuir en algunos supuestos el conocimiento de estos delitos de opinión a la jurisdicción castrense. No sólo suponía, pues, un importante recorte a la libertad de expresión, sino también un grave atentado a la unidad jurisdiccional, y por tanto una quiebra indudable del Estado de Derecho, además de fomentar la intervención del ejército en los conflictos sociales, como ocurriría durante la «Semana Trágica» de 1909. La Ley de Jurisdicciones fue muy contestada desde el momento mismo de aprobarse, en especial por los catalanistas, que ese mismo año de 1906 se agruparon en la plataforma electoral «Solidaritat catalana».

63 Cfr. Curso de Derecho Administrativo, op. cit. pp. 749 y ss. Vid, asimismo, L. MARTÍN REBOLLO, El proceso de elaboración de la ley de lo contencioso-administrativo de 13 de septiembre de 1888, Instituto de Estudios Administrativos, Madrid, 1975.

64 Cfr, sobre este extremo, G. DÍAZ, op. cit. p. 175. 
los asuntos relacionados con la educación se reflejan también en diversos trabajos y discursos, como el que pronunció en 1910 en la Real Academia de Ciencias Morales y Políticas con el título Sentido general en que debe llevarse a cabo la reforma de la enseñanza en España ${ }^{65}$.

Santamaría de Paredes colaboró con el Instituto de Reformas Sociales, creado en 1903 como un organismo suprapartidario, cuya presidencia se confió a Gumersindo de Azcárate y que contó con la estrecha colaboración de Adolfo Posada y de Álvarez Buylla. Uno de los vocales de este organismo, designados por el Gobierno (otros lo fueron por la patronal y por los sindicatos), fue Santamaría de Paredes, quien emitió diversos informes ${ }^{66}$. En realidad, la cuestión social, y muy en particular la situación de la clase obrera, siempre fue objeto de su interés, académico y político, desde una perspectiva reformista y moderada, propia del ya comentado «liberalismo armónico». No por casualidad su discurso de ingreso en la Real Academia de Ciencias Morales y Políticas, pronunciado en mayo de 1893, versó sobre El movimiento obrero contemporáneo. En él analizaba las etapas de este movimiento, tanto en su vertiente anarquista como marxista, así como sus tendencias y doctrinas ${ }^{67}$.

Sagasta, Azcárate, Moret fueron los más relevantes referentes políticos de Santamaría, sin olvidarse del «gran Castelar», como se refirió alguna vez al insigne republicano ${ }^{68}$, quien, fiel a su "posibilismo», ingresó en el Partido Liberal durante el primer Gobierno de Sagasta a comienzos de los años ochenta del siglo XIX. El «Liberalismo armónico» de Santamaría, aunque más conciliador, no era tampoco muy distante del que sostuvo José Canalejas, en quienes estuvieron depositadas desde 1910 a 1912 las esperanzas de la izquierda liberal, incluidos algunos destacados publicistas a extramuros de los partidos dinásticos, como los republicanos Azcárate y Melquíades Álvarez, quienes precisamente tras el asesinato de Canalejas fundaron el Partido Reformista, al que sumarían intelectuales de la talla de Adolfo Posada, Ortega y Azaña, mucho más críticos que Santamaría con el sistema político de la Restauración.

En 1903 fue elegido académico numerario de la Real Academia de la Historia $^{69}$. Por esos años el prestigio de Santamaría alcanza sus mayores cotas. Prueba de ello es que fue uno de los profesores de Alfonso XIII, y el más liberal, acaso

65 Citado por Y. BLASCO.

66 Como el que publicó en 1910, junto a F. MORA y P. P. DE ALARCÓN, sobre un complejo conflicto laboral que estalló en Gijón durante la primavera de ese año: Informe acerca del conflicto obrero-patronal de Gijón, Imprenta de la sucesora de M. Minuesa de los Ríos, Madrid, 1910.

67 Este discurso vio la luz ese mismo año en la madrileña tipografía de R. De.

68 La Política y la Moral, discurso leído en el acto de su recepción por el Excmo. Sr. D. Antonio López Muñoz y contestación del Excmo. Sr. D. Vicente Santamaría de Paredes, académico de número, el día 15 de diciembre de 1912. Establecimiento tipográfico «Sucesores de Rivadeneira», Madrid, 1912, p. 82.

69 Fue elegido exactamente el 6 de noviembre de ese año. Pero no tomó posesión, por lo que se declaró la vacante el 12 de diciembre de 1913. Recojo estos datos de la web de la propia Real Academia de la Historia. La verdad es que su aportación a la historiografía es irrelevante. 
el único, de todos ellos ${ }^{70}$. Designado por la Regente María Cristina, Santamaría impartió al joven Alfonso, entre 1900 y 1904, las nociones fundamentales del Derecho Público, pero también de la Economía Política. Con él visitó ese último año la Universidad Central, en donde tuvo ocasión de presentarle a otros miembros del claustro, entre ellos a Gumersindo de Azcárate. El monarca mostró un gran afecto hacia Santamaría, como lo atestigua el hecho de ser el único de sus profesores al que le escribió una extensa carta de agradecimiento y una foto con su dedicatoria «en prueba de cariño de su discípulo constitucional» ${ }^{71}$. Un discípulo bastante descarriado, desde luego, pues las interesantes reflexiones sobre la jefatura del Estado como «poder armónico» que le transmitió su maestro no fueron seguidas por este monarca. A este respecto Carlos Seco Serrano revela que en una ocasión Alfonso XIII, en vísperas de su acceso a la mayoría de edad, formuló a Santamaría la siguiente pregunta: « ¿ Y qué he de hacer cuando, en conciencia, la observancia de la Constitución se oponga a mis deberes para con España?» ${ }^{72}$. Se desconoce la respuesta del profesor, pero es muy probable que la pregunta le dejase muy inquieto.

Desde el 19 de noviembre de 1917 hasta el 9 de enero de 1919, Santamaría presidió el Consejo de Estado $^{73}$. Su nombramiento tuvo lugar cuando estaba al frente del Consejo de Ministros el liberal Manuel García Prieto. Durante 1918 éste se turnará en el cargo con Antonio Maura y el Conde de Romanones. Quizá más que a estos cambios políticos, la brevedad de su presidencia en el Consejo de Estado se debiese a la delicada salud de Santamaría, a la que me referiré más adelante.

El 26 de junio de 1920, año de su jubilación académica, Alfonso XIII, a propuesta unánime de la Facultad de Derecho de Madrid, cuyo decano era entonces Rafael de Ureña, le nombró Conde de Santamaría de Paredes, «como recompensa y coronamiento de una larga vida de grandes y múltiples servicios prestados a la ciencia y al Estado» ${ }^{74}$.

Tras una larga y angustiosa enfermedad, que había comenzado a manifestarse años antes de su jubilación y que le había obligado en varias ocasiones a suspender sus tareas universitarias ${ }^{75}$ y a dejar de frecuentar la Real Academia de Ciencias

70 Sobre este particular se extiende P. C. GONZÁLEZ CUEVAS en El Rey y la Corte, recogido en Javier Moreno Luzón (ed.) «Alfonso XIII. Un político en el Trono», Madrid, 2003, p. 94. Destaca González Cuevas que el resto de los preceptores eran militares o aristócratas, además de su confesor, el Padre Fernández Montaña, y el encargado de sus ejercicios espirituales, el jesuita Padre Coloma. Todos ellos muy conservadores e incluso integristas, como su confesor.

71 J. TUSELl y G. QUEIPO DE LLANO, Alfonso XIII. El Rey polémico, Taurus, Madrid, 2001, p. 111113 y nota 85 .

72 C. SECO SERRANO, La Restauración y sus «aperturas», Fundación Universitaria Española, Madrid, 1977, p. 206. Esta ilustrativa anécdota la tomó Seco Serrano de la biografía que Pabón dedicó a Cambó.

73 Así consta en los archivos del Consejo. Agradezco la información al profesor J. M. Bilbao, ex jefe del

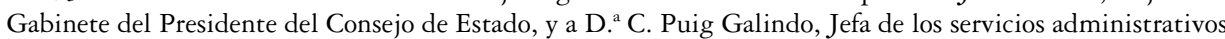
de este órgano.

74 Apud, C. FERNÁNDEZ-MIRANDA, op. cit., p.147.

75 Cfr. A. POSADA, Don Vicente Santamaría de Paredes, op. cit., p. 132. 
Morales y Políticas ${ }^{76}$, y acaso también, como queda dicho, a abandonar el Consejo de Estado, Santamaría murió en Madrid el 26 de enero de 1924, a los setenta años de edad, pocos meses después de que Primo de Rivera, espoleado por el monarca, liquidase de hecho la Constitución de 1876 y en realidad el régimen de la Restauración, del que Santamaría fue, como puede colegirse de lo antedicho, un destacado protagonista.

$$
* * *
$$

Title: An influential master of the Spanish Political Law: Vicente Santamaria de Paredes (1853-1924).

Abstract: Vicente Santamaria de Paredes was the most influential professor of the Spanish Political Law during the Restoration (1874-1923). Successor of Manuel Colmeiro and predecessor of Adolfo Posada in the chair of this academic discipline at the Central University of Madrid, their main works were the Curso de Derecho Politico and the Curso de Derecho Administrativo. Both were published for first time in the eighties of the nineteenth century and re-edited many times after. Santamaria had also an important activity as a lawyer, as a member of Parliament inside the Liberal Party, as a minister of Education in a Cabinet headed by Segismundo Moret and as preceptor of King Alfonso XIII. Santamaria promoted the Act which in 1888 carried out a deeply reform of the administrative jurisdiction and drew up the new functions of the Consejo de Estado. This essay deals with his career path, especially in the field of the Political Law.

Resumen: Vicente Santamaría de Paredes fue el más influyente cultivador del Derecho Político durante la Restauración (1874-1923). Sucesor de Colmeiro y predecesor de Adolfo Posada en la Cátedra de esa disciplina en la Universidad Central, sus principales obras fueron el Curso de Derecho Político y el Curso de Derecho Administrativo. Ambas vieron la luz por vez primera en los años ochenta del siglo XIX y fueron objeto de numerosas reediciones. Tuvo además Santamaría una notable actividad como abogado, como parlamentario en las filas del Partido Liberal, como ministro de Instrucción Pública y Bellas Artes en un Gobierno presidido por Segismundo Moret y como preceptor del Rey Alfonso XIII. A Santamaría se debe el impulso de la ley que en 1888 reformó la jurisdicción contencioso-administrativa y que trazó la nueva planta del Consejo de Estado. De su trayectoria, sobre todo académica en el ámbito del Derecho Político, se ocupa esta semblanza.

KeY words: Vicente Santamaría de Paredes, Spanish constitutional and political history, Spanish Political Law, Restoration.

Palabras clave: Vicente Santamaría de Paredes, historia constitucional y politica española, Derecho Político español, Restauración.

FECHA DE RECEPCIÓN: 30.06.2014 FECHA DE ACEPTACIÓN: 30.07.2014

76 Cfr. J. SÁNCHEZ DE TOCA, op. cit., pp. 29-30. Señala aquí este autor que, «en medio de todo, por el proceso de su enfermedad, la muerte ha sido para él una redención, porque para vivir como vivía, vale más buscar una vida mejor, como la que seguramente goza ahora». 